\title{
Mudanças Espaciais na Casa Republicana. A Higiene Pública e Outras Novidades
}

\author{
Maria Cecília Naclério Homem
}

Na virada do século, a República recém-proclamada propôs um novo programa político fundamentado, de preferência, na higiene pública. Assumiu o controle do espaço urbano e doméstico por meio de uma legislação rigorosa e da execução dos serviços relativos ao saneamento da terra e da água.

Em geral, a casa urbana permaneceu no alinhamento da rua, dependente de lotes populares, estreitos e alongados. Internamente, também preferiu a distribuição tradicional, feita no sentido frente-fundos, acrescida de entradas, de corredores laterais e de áreas internas.

A casa mais rica e ampla, dispondo de lotes maiores, introduziu espontaneamente recursos que melhor atenderam às propostas de higiene, tais como o recuo das divisas do lote e uma nova distribuição.

\section{Abstract}

In the beginning of the century, the recently proclaimed Republic (1889) proposed a new political program, based preferably on public hygiene. It took the control of the domestic and urban space by means of a strict legislation and the execution of works related to the sanitation of land and water.

The urban dwelling had difficulties in fitting the new utilizations on the whole it remained dependent on popular plots of land - narrow and elongated - as well as on the street alignment. Inside it also preferred the traditional distribuition, displayed in the front-backyard direction.

The rich and large dwellings, having bigger plots of land, introduced spontaneously resources to comply with the hygiene propositions, such as drawing back the boundaries of the plot and displaying a new distribuition.
Artigo elaborado com base na Tese de Doulorado "O palacete paulistano o processo civilizador e a morada de elite do café (18671914-18)", apresentada em novembro de 1992. Orientador: Prof. Dr. Carlos Lemos. 
(1) Lei estadual n. 240, de 4 de setembro de 1893.

(2) Apud FREYRE, Vicior da Silva. A cidade salubre. In: Revista Politécnica n. 48: p. 326, out./nov. 1914. Freyre refere-se a Daniel Bellel. professor das escolas superiores de Estudos Comerciais e de Ciências Políticas de Paris $\theta$ membro da Sociedade de Engenheiros Civis. Entre várias obras escreveu, em colaboraçáo com Guillaume Darvillé, Ce qui doit être la cité moderne. Paris, Bibliothèque des Actualités industrielles, 1914

(3) Márcia Lúcia R. Pinho Dias relacionou minuciosamente as leis com a casa operária: DIAS. Márcia Lúcia Rebello Pinho. Desenvolvimento Urbano e Habitaçao Popular em Sáo Paulo. 1870-1914. Sáo Paulo: Nobel, 1989

(4) LEMOS, Carlos A. C. Alvenaria Burguesa. Breve Historia da Arquitetura Residencial de Tijolos em São Paulo a partir do ciclo econômico liderado pelo café. 2. ed. Sáo Paulo: Nobel. 1989
A tônica predominante do desenvolvimento urbano e da casa republicana unifamiliar, do ponto de vista dos programas das necessidades ou dos usos, no período que antecedeu a I Grande Guerra, foram as tentativas de atender às soluções referentes à descoberta de que a limpeza, a aeração, a luz solar e o verde sāo tão importantes para a saúde e a sobrevivência do corpo humano quanto o pão e a água. O grande alvo era "o emprego dos meios tendentes a impedir a importação das moléstias epidêmicas e a disseminação das já existentes"

As moléstias em questão eram a febre amarela, a varíola, a peste, o impaludismo, a tuberculose, o cólera, o tifo, a gripe e outras motivadas pela falta de insolação e de saneamento básico, as quais grassaram nas cidades do século passado e dizimaram parte considerável de suas populações. Ainda, em 1914, o engenheiro Victor da Silva Freyre, professor da Escola Politécnica, apoiavase no corolário de Daniel Bellet (1809-1917) mediante o qual "o programa completo da construção das cidades limita-se ao seguinte: fazer penetrar o sol aos seus mais íntimos recessos" ${ }^{2}$

Tais tentativas foram observadas quanto à utilização da tecnologia no solo urbano e na habitação, na legislação ditada pelo Estado e pelo Município e nos elementos introduzidos espontânea e de modo independente pela casa mais rica e mais ampla da cidade, a qual denominamos palacete. Numa palavra, a casa republicana definiu-se a partir da gênese da higiene pública.

Neste artigo pretendemos demonstrar que a morada do período em questão: 1889-1914-18 consistiu em aliar tais elementos à tradição, numa gradação contínua entre esta e as novidades, de modo que podemos dizer que as alterações mais radicais ocorreram na casa mais abastada, em detrimento das mais pobres. Entre estas, apenas a casa média recebeu influência do palacete e, mesmo assim, de forma esporádica, como veremos adiante.

É nosso objetivo levantar os movimentos ou as coordenadas principais do periodo, em vista de estabelecermos uma visão do conjunto antes do que elaborar uma relação minuciosa entre as leis e a casa unifamiliar ${ }^{3}$

Em arquitetura, a ampla utilização de novos materiais e de novas técnicas construtivas como a alvenaria de tijolos, o ferro, o cimento, os tubos galvanizados e as calhas de folha de Flandres, as chapas de zinco e de cobre, arames e pregos galvanizados, telhas francesas, ardósia, Pinho de Riga, mármores, grades de ferro, guarda-corpos, janelas completas, mosaicos, etc. fabricados na Europa e transportados pela ferrovia, possibilitaram a criaçāo de novos espaços adequados às novas funções da casa e da cidade comercial que se industrializava ${ }^{4}$ Desse modo, colocou-se em desuso a taipa, técnica construtiva costumeira do Planalto Paulista, substituída, principalmente, pela alvenaria de tijolos.

O encontro das novas técnicas construtivas e dos novos materiais com os chamados estilos arquitetônicos historicistas como o Neoclássico, o Neogótico e o Neo-românico, e com os nacionais, os regionais e os pitorescos possibilitou a eclosão plena do Ecletismo entre nós. Esse movimento, ocorrido na arquitetura européia no decorrer do século passado, estendeu-se até a I Grande Guerra e correspondeu à auto-afirmação da burguesia. Importado diretamente da Europa, em São Paulo, acrescentaram-se àqueles estilos o art nouveau e até o Neocolonial, no começo do século. 


\section{O Higiene Pública}

Ainda em finais de Império, o Padrão Municipal e o Código de Posturas de 1886 significaram um passo adiante com relação ao de 1873 , quanto à higiene ${ }^{5}$ Foi o primeiro a interferir de forma direta nos programas da habitação, fixando o pé-direito das casas entre 5 e 4,5 metros; estabeleceu as medidas mínimas das portas, dos portōes e das janelas, bem como a espessura mínima das paredes (0,30 metro no primeiro pavimento). Aboliram as alcovas, devendo todos os cômodos ter abertura para o exterior. Tentaram disciplinar a construção dos cortiços, por serem focos de moléstias transmissíveis, bem como da casa operária, conforme veremos ainda. O Código proibiu o lançamento do esgoto na rua, ao mesmo tempo que procurou combater a poluição das águas e do ar, mediante a arborização das várzeas e da preservaçāo das matas próximas, já direcionando as casas de saúde para as zonas mais altas e salubres.

Tal legislaçāo revelou-se avançada para o seu tempo. Estava muito adiante de uma infra-estrutura urbana insuficiente, encontrando-se boa parte das casas sem fornecimento regular de água e com o esgoto a céu aberto.

Esse Código estipulou a abertura de ruas mais largas (16 e 25 metros), e permitiu os recuos fronteiros e laterais para as casas a serem edificadas fora do perímetro urbano e a construção de chalés nos bairros, assim como do sótão e de tetos à la mansard. Desse modo, constituiu importante marco para o Ecletismo em São Paulo.

Os anos subseqüentes à Proclamaçāo da República foram decisivos para a definiçāo da casa republicana. A Prefeitura modernizou rapidamente as suas leis. O Código Municipal de 1893 estabeleceu a aprovação das plantas das edificaçōes dentro dos critérios estipulados pelo Padrão Municipal.

Porém, o Estado ainda foi mais além. Desde 1892, passou a reformular e a ampliar continuamente o Serviço Sanitário, partindo de um conselho de saúde pública, de uma diretoria de higiene apoiada em laboratórios farmacêuticos, vacinogênicos e de análises químicas, bacteriológicas, além de um engenheiro sanitário e da introdução da prática da estatística demógrafo-sanitária. Quatro anos depois, aquele Serviço incluía uma polícia sanitária das habitaçōes particulares e coletivas, a fiscalização do exercício da medicina e da farmácia, um quadro de doze engenheiros sanitários, o serviço de desinfecção, hospitais de isolamento, lazaretos. etc. ${ }^{6}$ Em 1917, incluíram-se em seus quadros os institutos Butantã e Pasteur ${ }^{7}$

Nesse período, o Estado promoveu campanhas profiláticas e de erradicação das moléstias transmissíveis. Assumiu o saneamento da água e da terra, encampando a antiga Cia. Cantareira de Água e Esgotos, em 1892 e, dois anos depois, editou o Código Sanitário para orientar os municípios.

O Código estadual tornava o porão obrigatório como medida higiênica contra a umidade, proibindo o seu uso como habitação. Não permitia a construção das alcovas, determinava que cada dormitório tivesse 14 metros cúbicos e obrigava a cocheira e os estábulos a se distanciarem da habitação, para serem construídos fora da zona central. Eram proibidos os cortiços e cubículos no perímetro urbano, devendo as vilas operárias ser construídas fora das aglomeraçōes urbanas - no que nāo foi seguido. O solo deveria ser saneado primeiro para depois se proceder à construção desejada.

Regulamentou os esgotos, interditando o seu escoamento pelas calçadas e pelas vias públicas. Nas casas desprovidas de esgotos, toleravam-se as fos-
(5) Padrấo Municipal é de 11 de agosto de 1886 e o Codigo de Posturas é de 6 de outubro do mesmo ano.

(6) Lei n. 432 de 3 de agosio de 1896

(7) Lei n. 1.596 de 19 de dezembro de 1917 
sas fixas sempre que estivessem fora da habitaçāo, exceto quando existisse água potável ou poço.

A organizaçāo e a ampliação da rede de água e de esgotos e o aperfeiçoamento e a fabricação em série do equipamento sanitário como as torneiras, a privada sifonada, cuja patente era inglesa, a azulejaria, etc. permitiram a água corrente nos interiores e que a cozinha e o banheiro entrassem dentro de casa, bem como se transformassem em lugares limpos e desprovidos de umidade.

O novo Código determinava que as cozinhas ficassem longe da zona de repouso e, juntamente com os banheiros, deviam ter solo e paredes revestidas de material impermeável até 1,50 metro de altura, pelo menos. Em ambos os cômodos, as peças de louça tinham que ser fixas, esmaltadas e laváveis. Para a cozinha, estipulou o uso do sifão hidráulico interceptor e, para a latrina, o sifão com interceptor hidráulico, tornando-se obrigatório o fluxo de água da descarga.

Os relatórios do Serviço Sanitário do Estado e do Município procuravam redistribuir o espaço da cidade mediante sua divisão em zonas funcionais. Para tanto, valiam-se da topografia acidentada e do grau de salubridade que os terrenos proporcionavam.

A topografia irregular da cidade, conjugada com as antigas saídas e as ferrovias, foi propícia para o equacionamento dos problemas suscitados pela falta de higiene nos locais centrais da cidade onde se concentrava a populaçāo. Valorizaram-se as terras mais altas e saudáveis, em detrimento dos terrenos planos, cortados pelos rios e sujeitos às enchentes.

O grau de salubridade oferecido pelo meio ambiente encontrou-se no âmago da especulaçāo imobiliária e da estrutura interna da cidade. As moléstias temiveis eram encontradas de preferência nos bairros próximos às ferrovias, nos centrais como Santa Ifigênia e Bela Vista, e nos médios como Santa Cecilia, Vila Buarque e Consolação.

As terras mais altas, que estavam nas mãos de poucos, logo se valorizaram. A especulação imobiliária, interpretando os interesses dos mais poderosos, realizou diversos empreendimentos que foram, de preferência, iniciativas de europeus.

Numa cidade que passara de 47.697 habitantes em 1886, para 64.934 habitantes em 1890, entrando no novo século com 239.820 habitantes, assistiu-se à febre da construção civil e aos loteamentos que variaram conforme o tipo de usuário e a localização ${ }^{8}$

Ocorreu a valorização da zona aquém ferrovia, onde os terrenos colinosos eram mais secos, bem como daqueles que ficavam nas vertentes do espigão central do Rio Tietê. As chácaras ali existentes foram loteadas por especuladores que souberam interpretar os interesses das classes mais abastadas, realizando empreendimentos inspirados no urbanismo francês e providos de infra-estrutura urbana.

(8) ARAỦJO FILHO, J. R. A Populaçăo Paulistana no Século XIX. In: AZEVEDO, Aroldo de (org.) A Cidade de Sáo Paulo. Estudos de Geografia Urbana. Sáo Paulo: Nacional, 1958, v. 2.

(9) Parte do item Higienismo e o item Palacete foram extraídos de: HOMEM, Maria Cecilia $\mathrm{Na}$ clério. O Palacete Paulistano. O Processo Civilizador e a Morada da Elite do Café (1867 1914-18). Tese de Doutoramento à FAUUSP, em 1992.

\section{O Palacete}

O palacete correspondeu ao novo programa das necessidades proposto por uma sociedade comandada economica e politicamente pelos fazendeiros de café e demais empresários vinculados às atividades dependentes ou complementares da cafeicultura: comércio de exportaçāo, finanças e primeiras indústrias de bens de consumo, como tecelagens de algodão e aniagens ${ }^{9}$ 
Se por um lado a Grā-Bretanha liderou internacionalmente do ponto de vista econômico e tecnológico, na hora da escolha das soluçōes espaciais a França foi a grande favorita, independente da diversidade de estilos arquitetônicos trazidos a São Paulo pelo Ecletismo.

Podemos dizer que o palacete foi o grande precursor do sanitarismo abrindo caminho para o mesmo. No ocaso do Império, ele introduziu a casa afastada das divisas do lote, o zoneamento, isto é, o agrupamento das funçōes em três zonas distintas: estar, repouso e serviços, além da especialização do espaço. Rompeu-se a tradição pela qual a casa se situava no alinhamento da rua quando dentro do perímetro urbano, ainda em conformidade com o Código de Posturas de 1873.

Agora destinava-se um cômodo para cada função, existindo, inclusive, a sua subdivisão. Assim, a sala de jantar desmembrou-se em sala de almoço, em sala de comer das crianças, em sala de estudos, em sala da senhora, em sala de estar e em sala de costuras. O estar formal subdividiu-se em sala de visitas, em sala de música com o piano, em sala de bilhar e em "fumoir" Surgiram também o jardim de inverno, a biblioteca e a sala d'armas (sic). O gabinete manteve-se independente, assim como o quarto de hóspedes, tal como no antigo sobrado.

Os serviços passaram a incluir a cozinha, a despensa, o quarto de passar e engomar. Outra grande novidade foi o surgimento da copa ou "office" onde se captavam os pratos provenientes da cozinha e onde aguardavam a vez de serem servidos à francesa.

O supérfluo qualificou o novo espaço, cuja nomenclatura não mais deixou lugar à alcova nem à velha varanda (nome dado à antiga sala de jantar).

Internamente, o que caracterizava a casa tradicional, em especial o piso superior do sobrado destinado à moradia da família, eram também a superposição de funções e a localização do estar formal. Utilizado por hóspedes ou visitantes, esse permanecia separado pelas alcovas do estar informal ou familiar que transcorria na sala de jantar. Um corredor estabelecido no sentido frente-fundos levava os antigos escravos, os criados e os membros da família a cruzarem as diversas zonas. No morar tradicional, a sala de jantar gozava de situação sui generis. Muito mais ampla, situava-se entre a cozinha e as alcovas, para onde davam as portas das mesmas e as janelas do pátio de trás do sobrado. Superpunhiam-se ali uma série de funções. Além das refeições e de servir de passagem, ocorriam o estar familiar, a recepção a parentes e a amigos chegados, e tarefas como estudos, costuras, bordados, etc.

Por intermédio do palacete entraram o porão habitável, as edículas, a entrada social e a de serviços. Em 1891, reiterou-se a tendência à nāo superposição das funções mediante a distribuição francesa que propôs uma nova circulação. Com ela, a cozinha foi para o porão ou permaneceu em puxado no térreo.

Os jardins transformara-se em fonte permanente de ar e de luz. Quando fronteiros, serviram de anteparo aos odores e ruídos da rua. Os recuos proporcionaram perspectiva para a visão do conjunto da casa incluindo-se o jogo dos telhados. Gradís de ferro substituíram os muros e o palacete caracterizou-se pelo apuro estilístico.

Quanto à distribuição francesa, tratava-se de um procedimento da arquitetura que disciplinava a circulaçāo a partir do vestibulo ou do hall de entrada, de forma a tornar independentes as zonas de estar, de repouso e de serviços. Utilizava-se também da escada social que articulava ao vestíbulo a zona de 
repouso no primeiro andar e, por trás daquela, os serviços, que se situavam nos fundos da casa ou no porão. Existia uma variante do organograma francês que ligava a cozinha à sala de jantar apenas pela copa, onde a comida era entregue ao mordomo ou aos copeiros, evitando-se agitação, ruídos e odores.

As funçōes da casa concentravam-se em três zonas distintas: serviços, estar e repouso, que se ligavam pela circulação diversificada, pois que patrōes e criados deviam se encontrar o mínimo possível. Ao mesmo tempo, cada cômodo adquiria a sua independência, vinculado apenas ao vestíbulo ou a algum corred or ou ante-sala, os quais, por sua vez, só se ligavam à peça de distribuição. Além de isolar a zona de repouso, no primeiro andar, o estar formal separou-se do informal.

Extremamente requintado, tal procedimento atendia aos problemas de higiene da habitação e satisfazia o desejo de privacidade da parte da burguesia, bem como o da separação das classes sociais.

Francisco de Paula Ramos de Azevedo (1851-1928), arquiteto paulista dos mais atuantes na cidade de São Paulo, trouxe a distribuição francesa da Europa, após estudar Engenharia e Arquitetura na Universidade Real de Gand, na Bélgica.

Se a maior renovação no morar republicano ocorreu com o palacete, a incidência do mesmo foi pequena quando comparada ao conjunto das construções urbanas residenciais. Na pesquisa que estamos desenvolvendo na FAUUSP sobre habitação na cidade de São Paulo na I República, em colaboração com - CNPq - dirigida pelo arquiteto Carlos A. C. Lemos e coordenada por nós foram levantadas cerca de 3.000 plantas datadas de 1893-1906, pertencentes ao Arquivo Histórico Municipal Washington Luis, relativas a casas situadas nas ruas existentes na planta da capital de 1897. de autoria de Gomes Cardim.

Desse total, o professor Carlos Lemos idealizou o sorteio de 300 plantas que foram examinadas comparativamente e copiadas, considerando-se as dimensōes e os programas. Podemos dizer que nem 0,5\% desse total apresentou todas as características do palacete. Contudo, elas também apresentaram um passo adiante com relação ao novo morar, tendo incidido com maior ou menor intensidade nos demais tipos de casa do período: a casa média e a casa pequena (dita operária).

A casa média possuía alguns desses elementos mas não todos. À medida que aumentavam, ela crescia em importância. $\mathrm{Na}$ casa pequena, eles surgiram de modo esporádico, para ausentarem-se completamente nos cortiços, forma de habitação coletiva que seria o oposto do palacete, a saber: duas a quatro casas operárias possuindo áreas de uso comum com latrina e tanque coletivos.

A casa mais rica oscilou entre os elementos introduzidos pelo palacete e a distribuição tradicional, onde o estar ficava na frente, a zona de repouso no meio, seguida da sala de jantar e da zona de serviços. Neste caso, a sala de jantar era o centro da distribuição. Mas permanecia indecisa, ora mais próxima da cozinha, ora da sala de visitas, em seu afã em atender ao novo programa das necessidades, o qual estava a exigir a sua localização na zona do estar formal, destinada às recepções.

Para o palacete e esse último tipo de casa houve áreas exclusivas garantidas por leis municipais, que integraram os bairros mais elegantes loteados nesse período. A Avenida Paulista foi a pioneira. Em 1894, Joaquim Eugênio de Lima, um de seus empreendedores conseguiu uma lei obrigando as futuras construções a respeitarem um recuo de 10 metros com relação ao alinhamento das 
calçadas, bem como de 2 metros lateralmente ${ }^{10}$ Quatro anos depois, surgiram os recuos obrigatórios para jardins e arvoredo e um espaço de pelo menos 2 metros de cada lado para as residências a serem edificadas nas avenidas Higienópolis e Itatiaia (atual Avenida Angélica) ${ }^{11}$

\section{A Casa Média}

A casa média permaneceu entre a especialização do espaço introduzida pelo palacete e a distribuição tradicional. Quanto mais rica, maior o número de cômodos e a área construída, sendo menor a reversibilidade do espaço.

A casa média mais modesta possuía corredor lateral, áreas internas descobertas (saguōes) e jardins laterais, recursos utilizados para arejar os cômodos, os quais se generalizaram com a proibição das alcovas. As áreas internas e os pátios nos fundos já eram conhecidos dos paulistanos. Apesar de a maioria das casa urbanas do século passado ser geminada, possuindo aberturas na frente e nos fundos, Daniel P. Kidder, que aqui esteve em 1836, disse que todas as moradias eram construídas de modo a deixar uma área interna a fim de arejar os dormitórios ${ }^{12}$ Quando a casa média dispusesse de jardins fronteiros, ela se encontrava mais próxima do palacete.

O seu programa mínimo compreendeu 3 a 4 dormitórios, sala de visitas e quarto da criada. Era comum o gabinete, sempre na parte fronteira, próximo à sala de visitas, possuindo muitas vezes entrada independente, o que estava a indicar algum escritório de profissional liberal ou consultório médico. Na zona de serviços, a cozinha acoplou-se ao corpo de casa, no térreo, acrescida da despensa, do quarto da criada e do banheiro. Muitas vezes, essa zona contou também com quarto de passar ou de engomar, ou ainda de costuras.

Ocorreram variaçōes sobre aquele programa, ora aumentando o número de dormitórios e a área construída à qual se acrescentou parte do programa introduzido pelo palacete.

A sala de jantar manteve-se como centro da vida em família. O seu mobiliário indicava a tradicional superposição de funçōes. Além da mesa, das cadeiras, do buffet e da cristaleira, existiam, num canto, um sofá e duas poltronas, assim como a indefectível cadeira de balanço. Um relógio de parede cronometrava os compromissos e as tarefas do dia-a-dia ${ }^{13}$

A sala de visitas era cômodo obrigatório na casa média. Nela, o piano não podia faltar, ao lado do sofá, das poltronas e do tapete. A exemplo do palacete, muitas famílias mobiliavam-na com móveis dourados no estilo dos Luíses de França, fato que podia sugerir o refinamento cultural e o grau de sociabilidade dos moradores, quiçá na busca de compensar a ausência de uma sala de jantar destinada à formalidade do uso. Abertas para os estudos de piano, aos saraus e às visitas mais ilustres, a maioria dessas salas permaneceu fechada na maior parte do tempo, os móveis cobertos com guarda-pós brancos.

$\mathrm{Na}$ ausência da acomodação para criada e da sala de visitas, podemos dizer que estamos tratando da casa operária.

A casa média foi o gênero que predominou em São Paulo. Conforme a referida pesquisa, do total de 300 habitações, 183 apresentavam tais características, tendo sido preferencialmente térreas. Seguiu-se a casa mista, composta de armazém, loja e moradia, tanto térrea quanto assobradada, que apareceu em número de 80 . Os sobrados ocorreram com comércio no piso inferior e situavam-se nas esquinas dos quarteirōes de cada bairro. Era onde se instalava o
(10) Lei $n$. 111, de 21 de setembro de 1894

(11) Lei n. 355, de 3 de junho de 1898

(12) KIDDER, Daniel Parish. Reminiscências de Viagem e Permanência no Brasil. Apud. BRU. NO. Ernani da Silva. Memória da Cidade de Sáo Paulo. Depoimentos de moradores e visitantes 1553-1958. Sáo Paulo: Prefeitura Municipal, DPH 1981 (Série Registros 4).

(13) Dols romances descrevem muito bem a sala de jantar da casa média: DUPRÉ, Sra Leandro Eramos Seis Sao Paulo, Brasiliense 1946 e MESQUITA, Alfredo. Silvia Pélica na Liberdade Sáo Paulo Duas Cidades, 1979 
armazém de secos e molhados que garantia o abastecimento de gêneros alimentícios aos vizinhos.

A casa média, juntamente com a casa mista e operária, disseminou-se de modo sempre igual por toda a cidade, independente do bairro ou da funcionalidade da zona em que ela se encontrasse. Os exemplares ainda são inúmeros e podem ser localizados nos pontos mais antigos da capital.

Em 1914, Washington Luís Pereira de Souza, então prefeito da cidade, estabeleceu recuos fronteiros e laterais obrigatórios às construções particulares suburbanas $^{14}$ Sob sua gestão, os recuos também chegaram à Avenida do Tamanduateí, atual Avenida do Estado, (10 metros), já contando com recuos de 6 metros a Avenida Água Branca ${ }^{15}$

\section{A Casa Pequena dita Operária ou Popular}

A casa operária também foi chamada de "casa de italianos" por ter servido de moradia aos inúmeros peninsulares que passaram a afluir de modo intenso ao Estado de São Paulo e à sua capital desde as últimas décadas do século passado até pelo menos 1914, a ponto de torná-la conhecida como "cidade de italianos"16

Definiu-se tal tipo de casa como "cubos ou caixotes com decoraçāo aplicada ao gosto Neoclássico" uma vez que o estilo era sugerido pelos ornamentos arquitetônicos das fachadas, incluindo-se o art nouveau ${ }^{17}$ Sempre providas de platibandas, as fachadas distinguiam-se ainda pelas janelas altas e amplas que ficavam em posição elevada com relação ao nivel das calçadas. Por vezes, existiu um recuo lateral com portão de ferro. Tratava-se de uma casa construída por mestre-de-obras, pedreiro ou pelo próprio morador. Muitas vezes, ela apresentou-se geminada ou em séries enfileiradas, com porta ou portão e uma ou duas janelas, ocupando lotes estreitos e alongados ${ }^{18}$

A casa operária foi a menor habitação unifamiliar. Sucedeu a casa térrea de chão de terra batido ou de piso de tijolos, apresentando, na parte fronteira, um armazém e, nos fundos, a moradia.

(14) Lei n 1.788, de 28 de maio de 1914

(15) Respectivamente leis n. 1.780, de 7 de maio de 1914 e n. 1.422, de 12 de maio de 1911

(16) De 1877 a 1914 , entraram no Estado de Sá Paulo 1.728.520 imigrantes, dos quais 845.816 eram italianos, fixando-se boa parte capital. In SENAI, Franco Italianos no Brasil. "Andiamo in'Mérica". Săo Paulo: Mantins, 1953 (?), p.172. Foi Alf́redo Moreira Pinto quem definiu Sáo Paulo como "cidade de italianos" Vide PINTO, Alfredo Moreira. A Cidade de Sáo Paulo em 1900. Impressర6es de Viagem. Rio de Janeiro, Impr. Nacional, 1900

(17) DEBENEDETTI, Emma e SALMONI, Anita. Architettura Italiana a San Paolo. Sáo Paulo: Instituto Cultural Ítalo-Brasileiro, 1954. p. 36

(18) Idem e DIAS, Márcia Lúcia R. Pinho. op cit p. 74

(19) Leis $n .498$, de 14 de dezembro de 1900 e n. 1.788 , de 18 de maio de 1914 .
Caracterizou-se por um programa das necessidades mínimo, onde se concentravam as funçōes básicas correspondendo à sala na frente, quarto no centro, seguido de sala de jantar e cozinha. Geralmente a latrina ficava nos fundos, no quintal, além do tanque. Não raro, podia dispor de uma cocheira. Mas houve também variaçōes sobre o mesmo tema e casas que nem mesmo contavam com esse programa, ora faltando a sala de jantar, ora a sala de visitas. Nesse caso, esta era substituída por um armazém ou loja.

O Padrão Municipal de 1886 estipulou-lhe o mínimo de três cômodos, inclusive a cozinha, medindo cada um pelo menos 7,50 metros quadrados e devendo todos eles possuir abertura para o exterior.

A aeração fazia-se pelas janelas fronteiras, pelos corredores laterais, pelas áreas internas ou pelo quintal. Geminada e quase sempre no alinhamento da rua, houve também as que tiveram um recuo fronteiro de 4 metros dedicado a um jardinzinho. Apareceu ainda isolada, em meio a terrenos de chácaras, destinados ao cultivo de hortaliças e de flores. Em 1900, procurou-se impor os recuos de 5 metros para as vilas operárias, edificadas no perímetro suburbano, onde a lei também procuraria fazer chegar o recuo lateral de 1,50 metro e o fronteiro, de 4 metros, catorze anos depois ${ }^{19}$ 
Por se tratar de lotes muito estreitos (6 metros e até 4,40 metros), e de pés-direitos muito altos, a casa operária quase não pode atender à necessidade de uma insolação mínima de 3 a 4 horas diárias ${ }^{20}$

A sala de visitas manteve-se sempre na frente da casa. Por sinal, era o cômodo mais arejado, provido de janelas que davam diretamente para a rua. Com freqüência, era reversivel, transformando-se em dormitório, mesmo a sala de jantar. Abrigavam hóspedes ou recém-chegados do exterior ou desempregados. Nesses casos, a sociabilidade era resolvida na calçada para onde se levavam as cadeiras, à noite, a fim de se tomar a fresca e se proceder ao convivio com os vizinhos e conhecidos do bairro.

Conforme a referida pesquisa, a casa operária representou pouco mais que $10 \%$ do total das casas paulistanas levantadas, enquanto que a casa mista, $24 \%$ e o cortiço, $5,4 \%$ do mesmo.

Para concluir, podemos observar que, com a ferrovia e a introdução da tecnologia no solo urbano no governo provincial de João Teodoro Xavier (18721875), iniciou-se a mudança nos programas das necessidades da casa paulistana. Porém, com a República, mais se acentuou a renovação no morar. Nesse momento, o Estado interferiu de modo direto no espaço urbano e doméstico procurando executar o programa econômico da cafeicultura, segundo o qual era necessário sanear o meio tropical e impedir que grassassem as moléstias que vinham do exterior com o objetivo de atrair capitais e mão-de-obra estrangeira. Culturalmente, a classe dominante dos empresários do café esteve vinculada de preferência à França de onde importou o palacete. Este também introduziu soluçōes capazes de sugerir mudanças, ainda que de modo dispersivo, nos demais tipos de casas e de reformular a idéia de morar em conformidade com os mais modernos princípios sanitários.

A Higiene Pública impôs renovações às casas menores, as quais, no entanto, não puderam ser resolvidas a contento. Tais habitaçōes estiveram mais perto da circulação tradicional, tendo contado também com lotes alongados e estreitos, que mal deixavam espaço para os recursos imprescindiveis: corredores laterais e áreas internas.

A casa média permaneceu indecisa. Da casa rica recebeu certas sugestões como a subdivisão das funções e os jardins laterais e fronteiros. Mas não se desvencilhou da antiga circulação. A sala de jantar ocupou sempre o centro da composição espacial, o que indica que persistia a sua função aglutinadora do viver familiar. A sala de visitas constituiu o seu ponto de honra, pelo qual ela procurou compensar a distância que manteve do palacete. Com freqüência, ampliou a área construída e o número de cômodos, aos quais atribuiu funçōes novas introduzidas por aquele.

Além dos recursos supracitados, a casa popular incorporou apenas a latrina no fundo do quintal e o tanque junto à cozinha. Substituiu os termos varanda e alcova respectivamente por sala de jantar e quarto. Essa esteve sempre presente, assim como a sala de visitas, muito embora não raro se transformassem em dormitórios. Nesse caso, a sociabilidade era resolvida na calçada, em frente à casa. Os jardins fronteiros foram esporádicos, apesar das tentativas feitas pela legislação municipal no sentido de incorporá-los definitivamente às casas particulares suburbanas.
(20) Vide artigo supracitado de Victor da Silva Freyre 


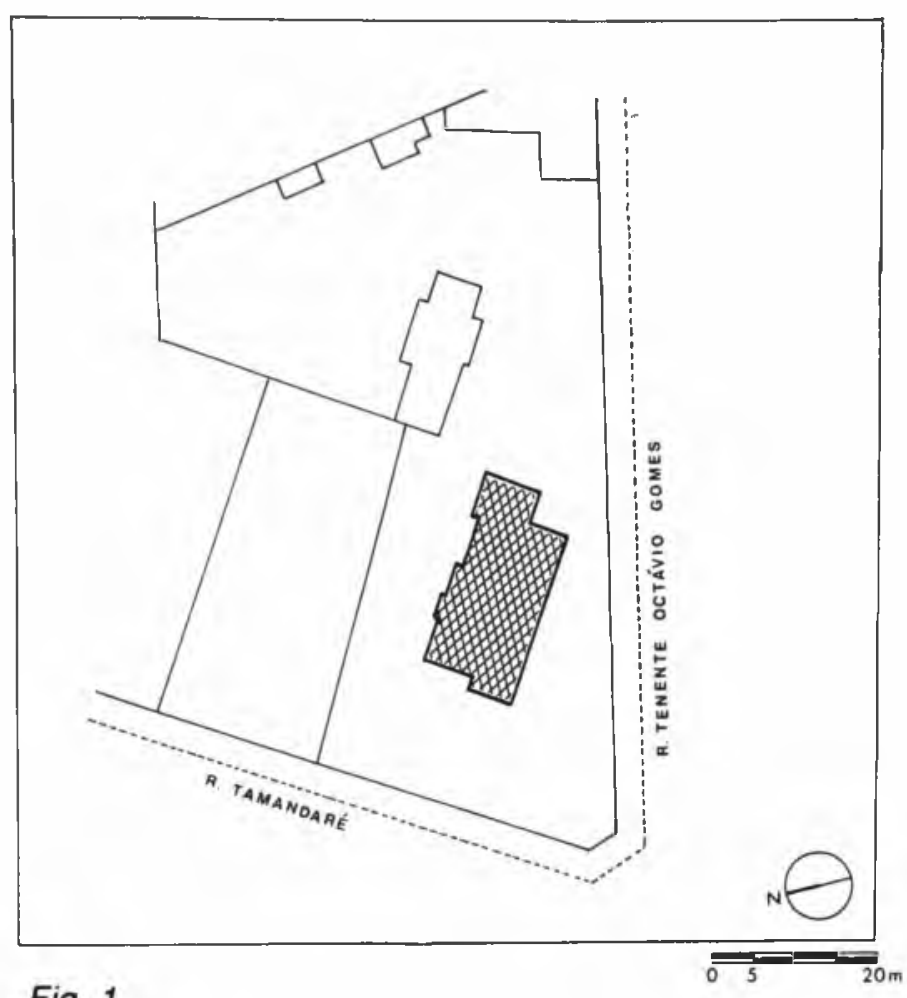

Fig. 1

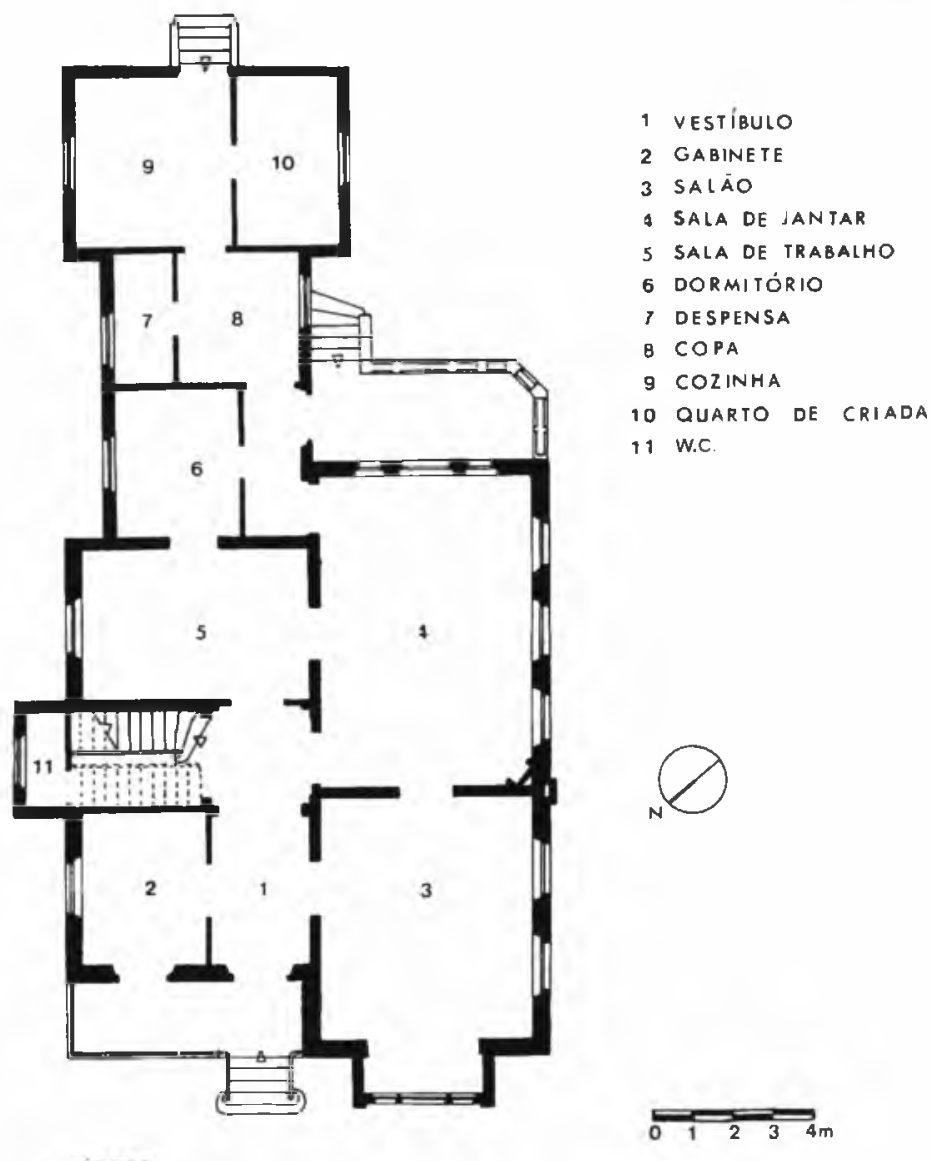

Fig. 3

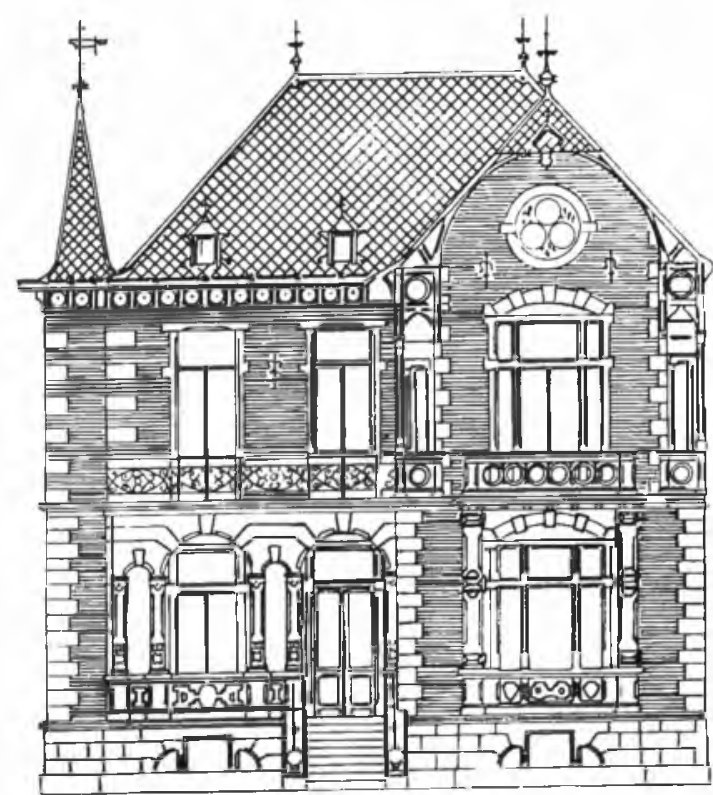

ELEVAÇÃO PRINGIPAL

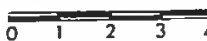

Fig. 2

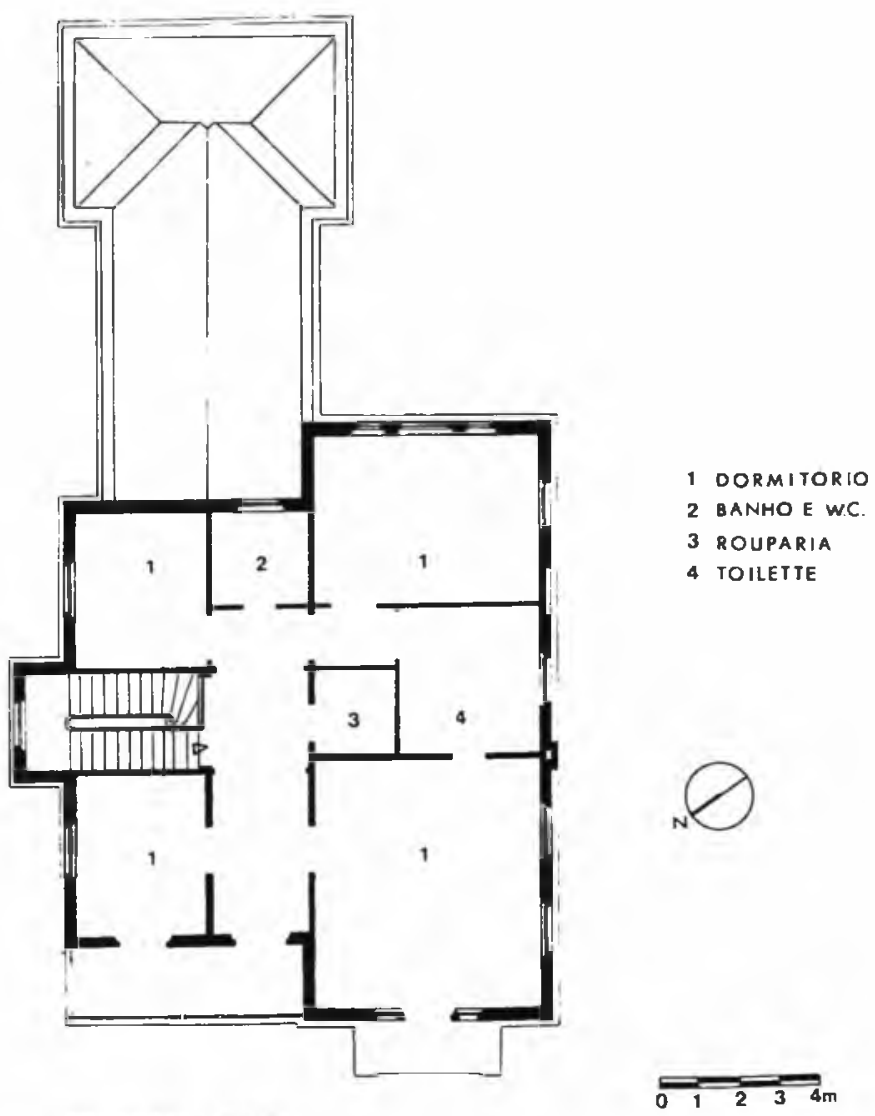

Fig. 4

Figs. 1, 2, 3 e 4

Casa 1

Projetado e construído por Ramos de Azevedo, com apuro estilístico e implantação em meio a jardins, o palacete da Condessa de Parnaíba foi um dos pioneiros da cidade. Possuía o esquema básico da distribuiçāo francesa, mas a sala de jantar ainda aparecia como distribuidora da circulação para a zona de serviços.

A cozinha ficava em puxado no térreo e o w.c. debaixo da escada, de acordo com o costume francês. O primeiro andar já contava com um banheiro completo, mas persistiram os quartos de toilette e 0 uso dos urinóis como complemento àquela novidade.

Fonte: Arquivo do Escritório Técnico "Ramos de Azevedo", na Biblioteca da FAUUSP. Extraída de HOMEM, Maria Ceclila Naclério. O Palacete Paulistano. 1992. 


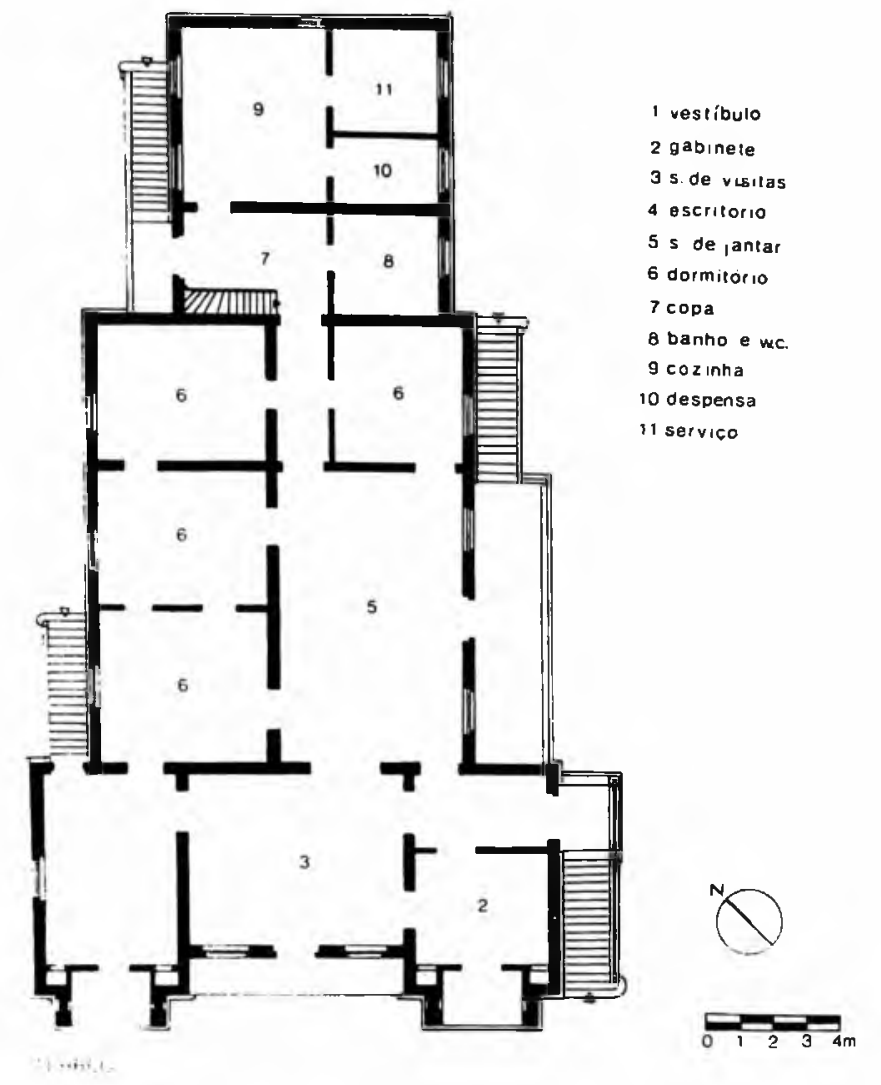

Fig. 5

Casa 2

Planta de casa rica oscilando entre a tradição e o palacete. Situada na Avenida Paulista, n. 97, os arquitetos August Fried e Carlos Ekman projetaram e construíram esta casa térrea com porão, em meio a jardins, para José Borges de Figueiredo.

A sala de jantar, entre os dormitórios, permaneceu como centro distribuidor. A exemplo de antigo sobrado, o gabinete e os cómodos destinados à sociabilidade ficaram na parte fronteira. $O$ banheiro, no agenciamento da cozinha, evidenciava a dependéncia do uso dos urinóis guardados nos criados-mudos dos quartos, bem como a sua passagem obrigatória pela sala de jantar e pela copa até chegar ao w.c., onde se despejavam os respectivos conteúdos.

Fonte: Arquivo Histórico Municipal Washington Luís e apresentada em HOMEM, Maria Cecília Naclério. O Palacete Paulistano. 1992.

Fig. 7

Casas 4 e 5

Plantas de duas casas médias geminadas, na Rua da Consolaçăo, pertencentes à Santa Casa da Misericórdia.

Situavam-se no alinhamento da rua, com entrada lateral e contavam com quintais e áreas internas, por onde se fazia a aeração dos cômodos, recursos utilizados em vista de se atender às exigências estipuladas pelos Códigos Sanitários.

O programa das necessidades era o básico para esse tipo de casa: sala de visitas e gabinete fronteiros, seguidos de três dormitórios, interligados por um corredor estabelecido no sentido frente-fundos. A sala de jantar, mais ampla, constituía o centro da casa, local onde ocorria a vida familiar.

Como as demais residencias imediatamente anteriores, havia incompatibilidade da antiga casa urbana quanto ao atendimento dos novos programas.

Fonte: Arquivo Histórico Municipal Washington Luís.

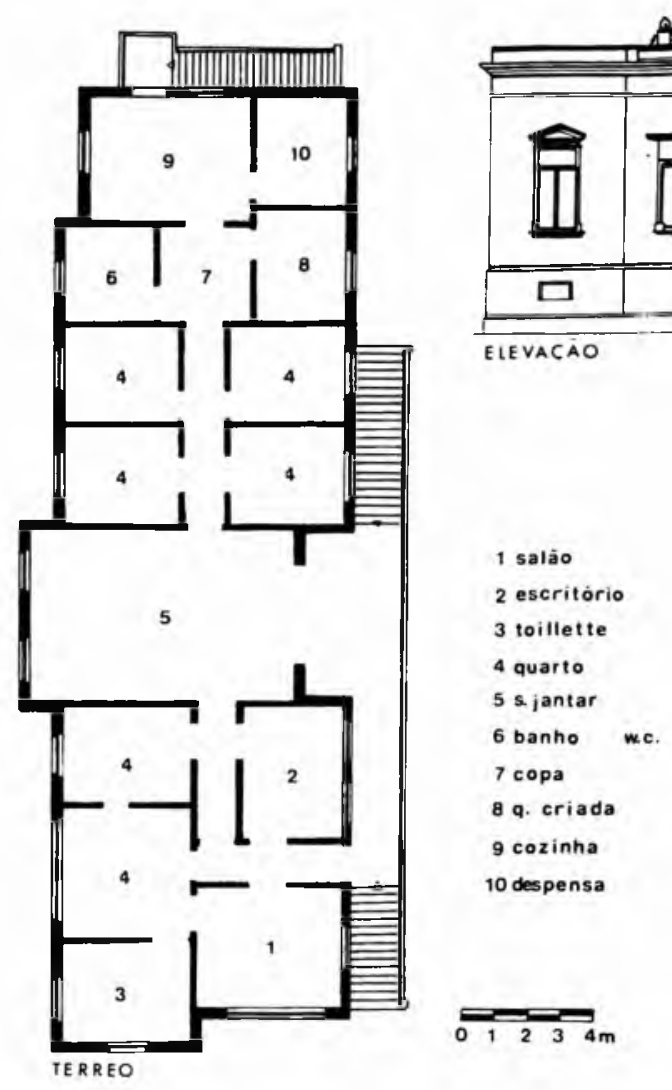

Fig. 6

Casa 3

Situada na Avenida Higienópolis, n. 14, esta casa térrea com porāo semi-enterrado pertenceu a Antonio Batista de Campos Pereira e foi construida em 1904, com recuos fronteiros e laterais, conforme a lei de 1898. Possuía ainda as características da anterior.

Fonte: Arquivo Histórico Municipal Washington Luis.

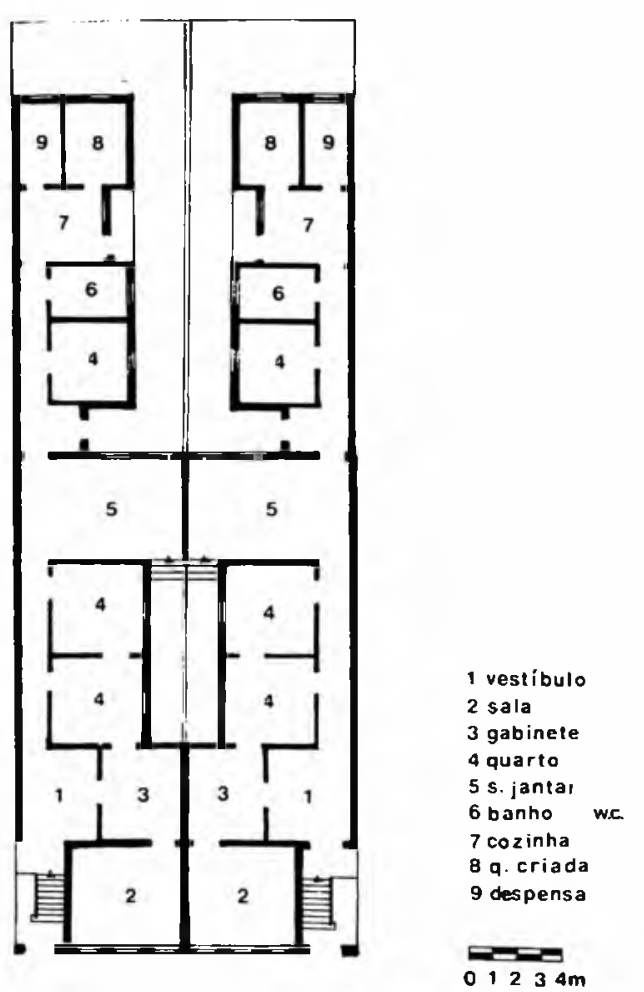




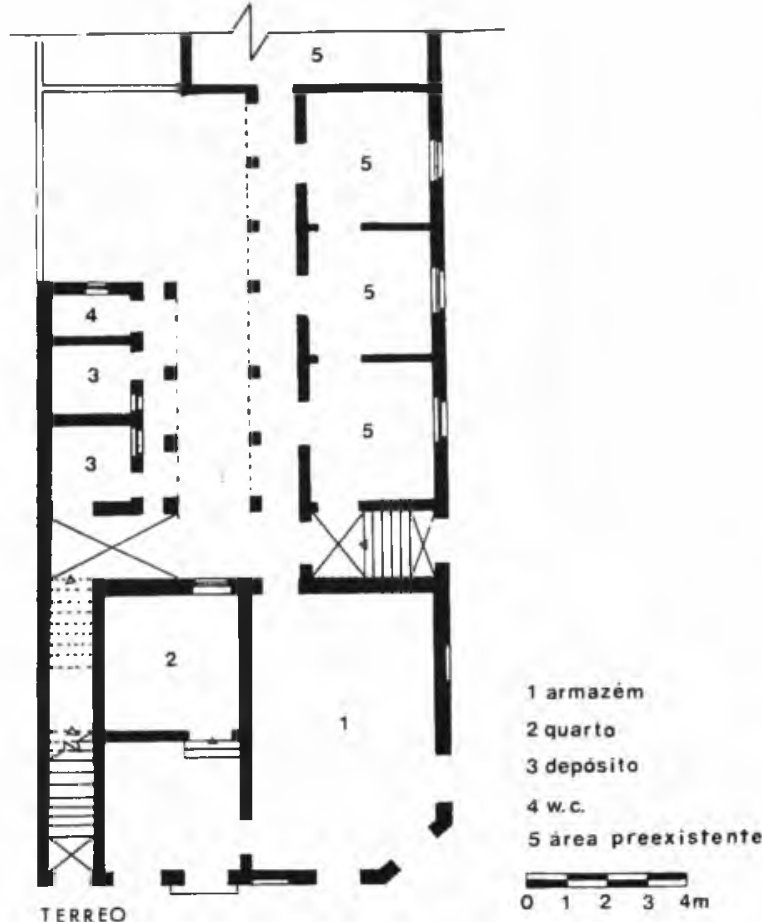

Fig. 8

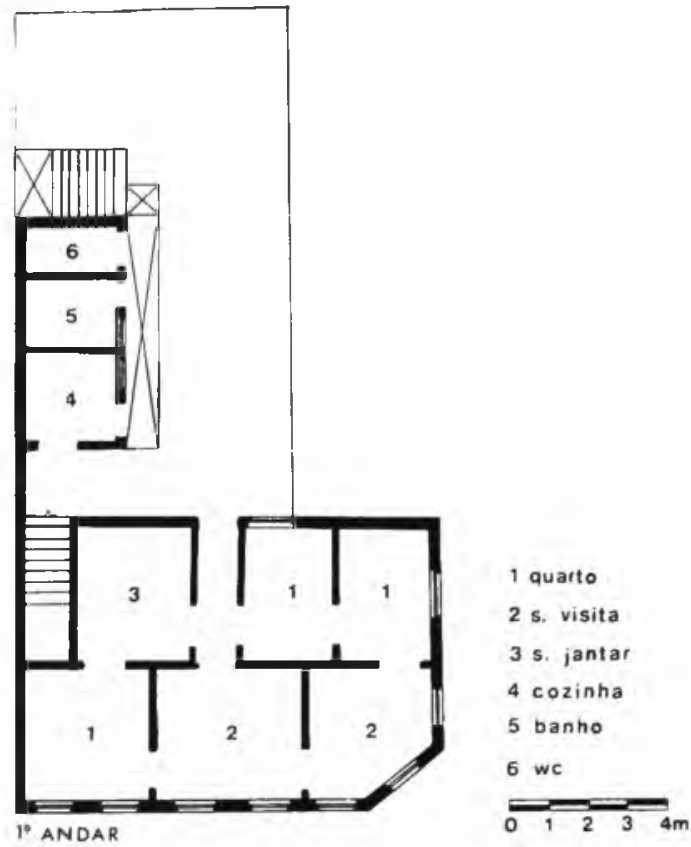

Fig. 9

Figs. 8 e 9

Casa 6

Apresentamos um exemplo de sobrado de esquina com armazém no térreo com demais dependências para esse tipo de comércio e moradia no andar superior. Datado de 1904, pertenceu a Miguel D'Andretta e localizava-se na Rua da Consolação esquina com a Alameda Santos, n. 403.

Fonte: Arquivo Histórico Municipal Washington Luls.

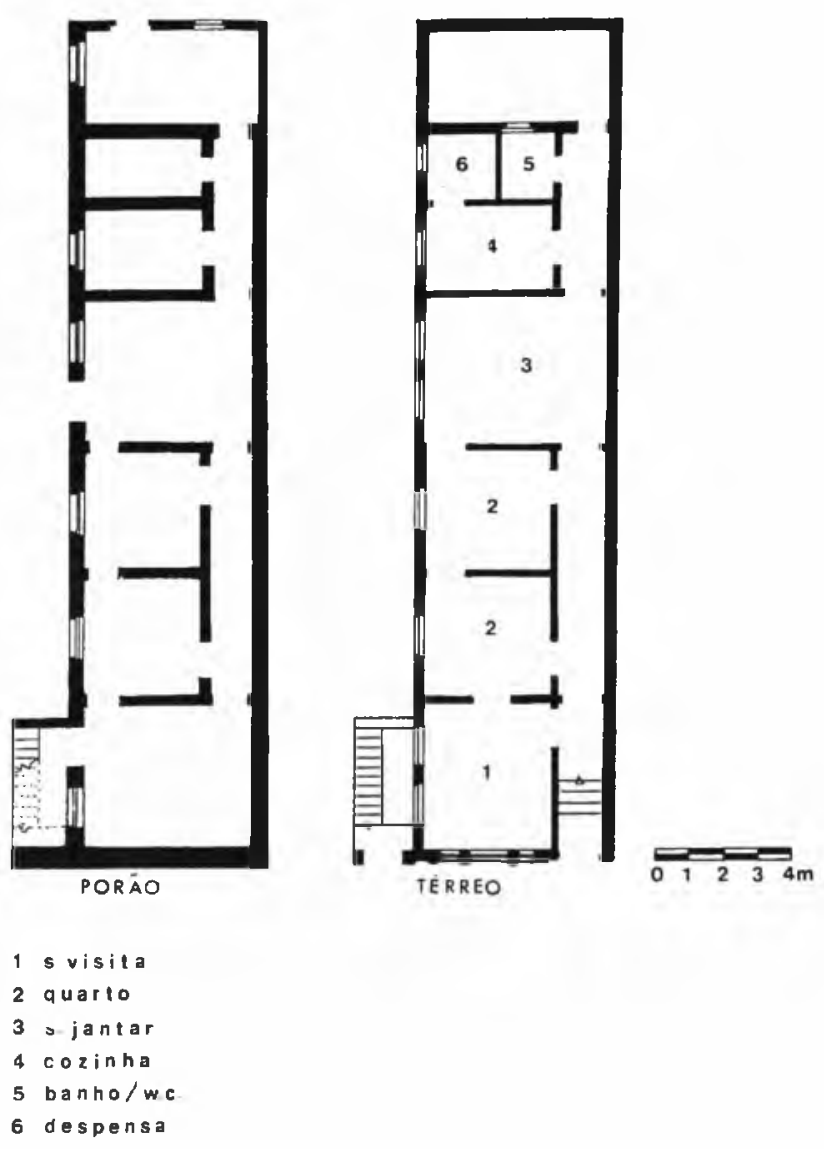

Fig. 10

Casa 7

Casa térrea com porāo, de Achille Bauduin na Rua da Glória, n. 138. Provida de entrada e quintal, para os quais davam as aberturas dos cómodos, constitui exemplo de casa oscilando entre a média e a operária. A sala de jantar era sempre mais ampla. 0 banheiro ficava no agenciamento da cozinha. A ausência de acomodaçāo para a criada remete-nos à casa operária, muito embora fosse provida de sala de visitas na frente, possivelmente Iransformada em quarto, dado o pequeno número dos mesmos.

Fonte: Arquivo Histórico Municipal Washington Luis. 


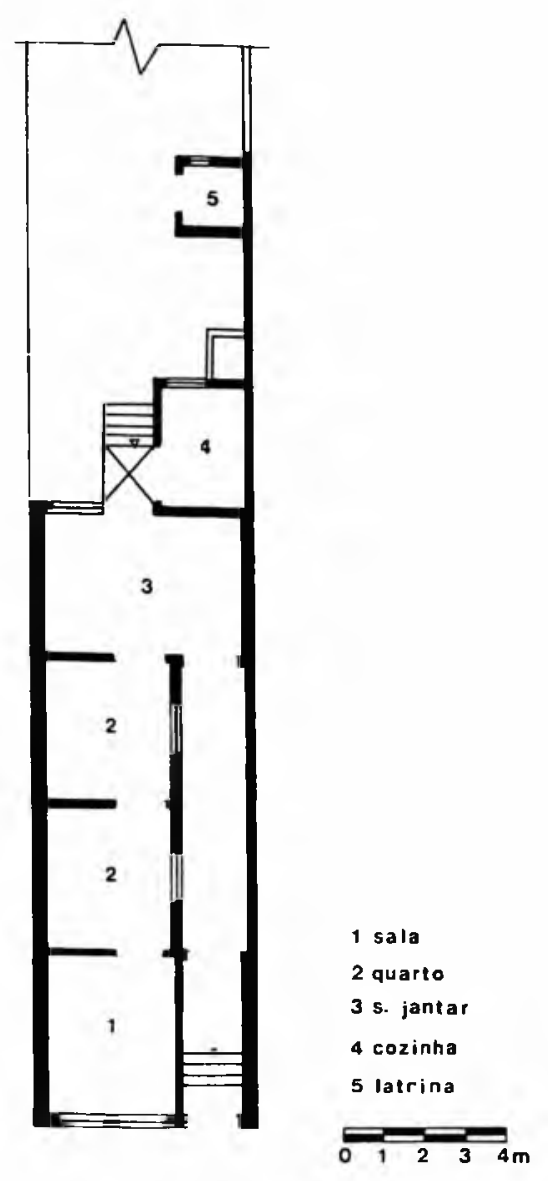

Fig. 11

Casa 8

Exemplo de casa operária de 1903. Pertenceu a Umberto Zumkellere e situava-se na Rua Lopes Chaves, n. 57, no Bairro da Barra Funda. Dispunha de corredor lateral, para resolver os problemas de higiene da habitação, sala de jantar mais ampla, além do tanque e da latrina no quintal.

Fonte: Arquivo Histórico Municipal Washington Luís.

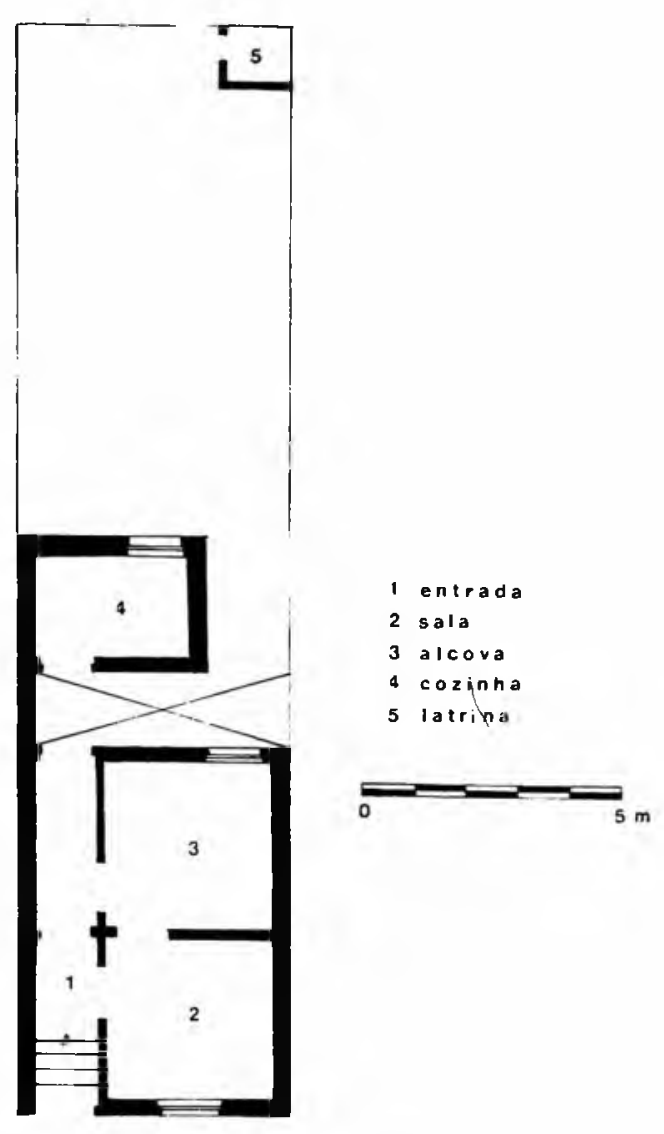

Fig. 12

Casa 9

Casa popular de J. Manoel Lembo Gonçalves, na Rua Bresser, no Brás. Construida em 1898 , dispunha de área interna descoberta, outro recurso utilizado para atender ao Código Sanitário de 1894. Note-se o emprego da palavra alcova para designar dormitório.

Fonte: Arquivo Histórico Municipal Washington Luís.

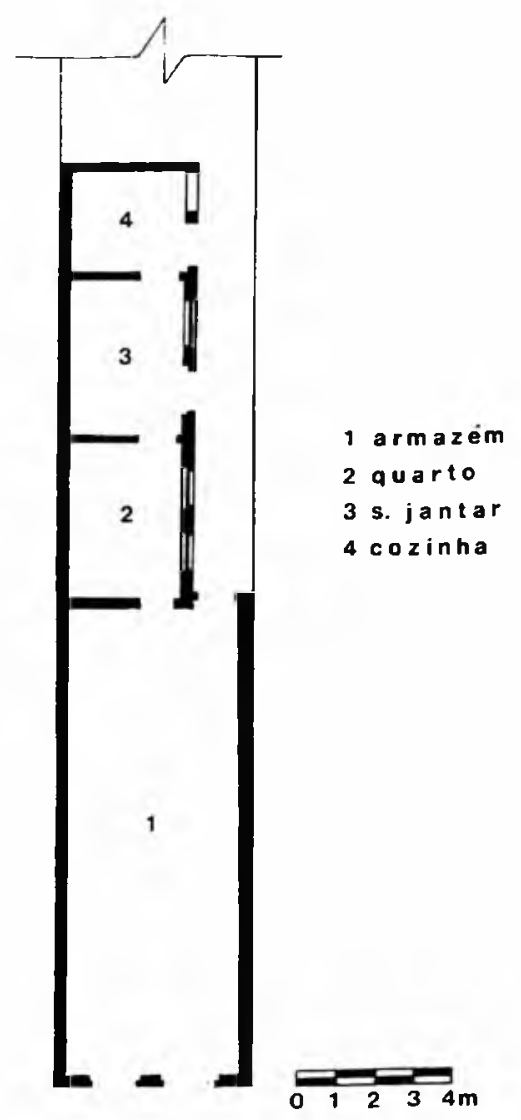

Fig. 13

Casa 10

Casa térrea mista para Charles Weller, na Rua Caetano Pinto, n. 49, no Brás. Construida em 1903, por Miguel Marzo, em lote exiguo, dispunha de armazém fronteiro e de quintal para resolver os problemas de higiene.

Fonte: Arquivo Histórico Municipal Washington Luís.

Obs.. As plantas dos desenhos apresentados foram copiados e padronizados por Regina Mitie Suzaki e Ilza Fujimura.

\section{Arquivos Consultados}

Arquivo Histórico Municipal Washington Luis - setor de plantas encadernadas sob a designação de Livros de Obras Particulares.

Arquivo de Plantas do Escritório Técnico Ramos de Azevedo, na Biblioteca da FAUUSP

\section{Bibliografia}

AZEVEDO, Aroldo de (org.). A Cidade de São Paulo. Estudos de Geografia Urbana. São Paulo: Nacional, 1958. $4 \mathrm{v}$.

BRUNO, Ernani da Silva. Memória da Cidade de Sáo Paulo. Depoimentos de Moradores e Visitantes, 1553-1958. São Paulo: Prefeitura Municipal, DPH, 1981 (Série Registros 4).

DEBENDETTI, Emma, SALMONI, Anita. Architettura Italiana a San Paolo. São Paulo: Instituto İtalo-Brasileiro, 1954. 
DIAS, Márcia Lúcia Rebello Pinho. Desenvolvimento Urbano e Habitação Popular em São Paulo 1870-1914. São Paulo: Nobel, 1990.

DUPRÉ, Sra. Leandro. Éramos Seis. São Paulo: Brasiliense, 1946.

FREYRE, Victor da Silva. A Cidade Salubre. Revista Politécnica, São Paulo, n. 48, p. 319-154, nov. 1914.

HOMEM, Maria Cecilia Naclério. O Palacete Paulistano. O Processo Civilizador e a Morada da Elite do Café (1867 - 1914-18). Tese (Doutoramento), 1992. Faculdade de Arquitetura e Urbanismo. Universidade de Sāo Paulo.

LEMOS, Carlos A. C. Alvenaria Burguesa. 2. ed. São Paulo: Nobel, 1989.

MESQUITA, Alfredo. Silvia Pélica na Liberdade. São Paulo: Duas Cidades, 1979.

PRADO JR., Caio da Silva. A Cidade de São Paulo. 13. ed. São Paulo: Brasiliense, 1983.

SẢO PAULO (Cidade). Códigos de Posturas. Sāo Paulo, s.n., 1873 e 1886.

- Leis e Atos do Município. Sāo Paulo. Vanhorden, 1903-1914.

. Leis e Resoluçōes da Câmara Municipal. Sāo Paulo, Vanhorden, 1892 a 1918.

SĀO PAULO (ESTADO). Leis e Decretos. São Paulo, IMESP 1889 a 1918. 